Methods We present as indicators in the development of genocide: for example, language change, devaluation of others, polarisation, inequality, discrimination, riots, weapons available, medical experiments, and murdering without legal prosecution.

Results The development of genocide can be described with indicators. By using these indicators areas of differing risk for genocide could be defined in other regions of the world. We will apply these indicators to selected examples of countries.

Conclusion Indicators can be useful for scoring countries at risk. Violence control programmes could operate within this framework of stages for mapping violence.

\section{SP2-4 IMPACT ASSESSMENT OF INSTITUTIONAL CAMPAIGNS COMPARED TO SUMMER MONTHS ON THE SEARCH FOR INFORMATION ABOUT SELF-EXAMINATION OF THE SKIN}

doi:10.1136/jech.2011.142976n.94

${ }^{1,2} \mathrm{P}$ R Vasconcellos-Silva, ${ }^{*} \mathrm{R}$ H Griep, 'L D Castiel. ${ }^{1}$ Oswaldo Cruz Foundation, Rio de Janeiro, Brazil; ${ }^{2}$ National Cancer Institute, Rio de Janeiro, Brazil

Introduction The analysis of log files of qualified websites has become recently a simple way to estimate the collective demand for health information. We analysed the access to the Brazilian National Cancer Institute (INCA) website to estimate the impact of perception of sun exposure in summer as well as the influence of national campaigns on the search for information about selfexamination of the skin (SES).

Methods The INCA's website was selected by its popularity and volume of qualified information. We studied 4800 pages over 4 years (January 2006 to December 2009) by means of a log analyser to estimate the access to pages related to SES during institutional campaigns compared with the summer months in southern hemisphere.

Results The average number of hits in the summer months were 1037; 1609; 2275 and 2529 hits (2006 to 2009, respectively) indicating an audience below the annual average (1131; 2013; 2741; and 2827). On the other hand, there was more access to pages about SES in the months of the national campaigns (1710; 2640; 3722 and 3197 hits) surpassing the annual average.

Conclusions In Brazil, the perception of sun exposure during the summer months seems to be not sufficient to arouse great interest in the SSE. We affirm the opposite in relation to institutional campaigns, which seem to arouse more interest about skin cancer early detection on the internet.

\section{SP2-5 DIABETES IN ASIA: A HYPOTHESIS}

doi:10.1136/jech.2011.142976n.95

${ }^{1,2} \mathrm{C}$ M Schooling, ${ }^{2} \mathrm{G}$ M Leung. ${ }^{1}$ CUNY, New York, USA; ${ }^{2}$ The University of Hong Kong, Hong Kong, China

Introduction With rapid economic development, diabetes is reaching epidemic proportions in Asia, even in relatively non-obese populations. Changing lifestyles, obesity and genetics undoubtedly play a key role, however it is increasingly recognised that causes of disease may extend over generations.

Methods The developmental origins of health paradigm has focused on the health consequences of constrained pre-natal or infant growth. Here we consider the complimentary question of constrained pubertal growth. Specifically, we examined the physiological and biological consequences for long-term health of constrained pubertal growth.

Results Generations of constrained environments, common in Asian countries such as China, Indonesia or India, may increase vulnerability to diabetes, via low pubertal sex-steroids and hence low muscle mass. Furthermore, this hypothesis is consistent with the observed negative associations of diabetes with some hormonally related cancers and the sex-specific associations of diabetes with cardiovascular diseases.

Conclusion We offer a hypothesis for conceptualising diabetes in developing populations and the aetiology of diabetes in all populations with corresponding practical and testable implications for diabetes prevention

\section{SP2-6 MAINTAINING LOCAL PUBLIC HEALTH IN THE GLOBAL CONTEXT: A SUSTAINABLE IMMIGRANT HEALTH SCREENING SYSTEM IN A STATE WITH AN IMMIGRANT MAJORITY}

doi:10.1136/jech.2011.142976n.96

0 Harrison, ${ }^{*}$ F Ahmed, FAl Hosani, A Al Mannaie. Health Authority of Abu Dhabi, Abu Dhabi, United Arab Emirates

Introduction The 1981 Ministry of Health law of United Arab Emirates mandates health screening of all immigrant residents above 18 years of age at initial visa issuance and visa renewal every 3 years. Screening is done for five communicable diseases. The Health Authority of Abu Dhabi (HAAD) which is the healthcare regulatory body is responsible for implementation of the visa screening law in the Emirate. Annually, about one million applicants including new and old immigrants undergo screening at seven certified centers in Abu Dhabi. This report discusses the improvement in the health screening process and the 2010 prevalence of HIV infection among the immigrants in Abu Dhabi.

Methodology In 2009, HAAD upgraded the visa health screening system by issuing screening standards for the delivery of efficient and standardised clinical services. Concomitantly an Oracle-based information system was established for rapid and reliable data collection and generation of real-time reports.

Results Following system upgrades, the screening capacity increased from 1500 to 5000 applicants daily and time for issuance of fitness certificate decreased from $48 \mathrm{~h}$ to $2 \mathrm{~h}$ over 2 years.

There were 935233 applicants screened in 2010 including 56\% new visa applicants and $20 \%$ females. The prevalence of HIV infection was 25 and 7 per 100000 among the new and old immigrants respectively $(\mathrm{p}<0.001)$.

Conclusion The Abu Dhabi immigrant health screening has improved particularly the applicant turnaround time, data availability and reliability. The process could be adopted by health systems with similar visa screening requirements.

\section{SP2-7 PRESCRIBING OMISSIONS OF CARDIOVASCULAR RISK MANAGEMENT THERAPY IN ELDERLY PATIENTS ADMITTED TO A STROKE UNITY}

doi:10.1136/jech.2011.142976n.97

${ }^{1}$ E Borges, ${ }^{1}$ A F Macedo. ${ }^{*}$ Faculty of Health Sciences, University of Beira Interior, Covilhã, Portugal; ${ }^{2}$ Health Sciences Research Centre, University of Beira Interior, Covilhã, Portugal

Introduction Drug-related problems (DRPs) are common in elderly patients, the majority being preventable. Several criteria have been published to help clinicians identify DRPs due to inappropriate prescribing. However, few studies provide criteria to help clinicians identify underuse of medication considered beneficial. This study aimed to quantify and characterise prescribing omissions of cardiovascular risk management therapy using START (Screening Tool to Alert Doctors to the Right Treatment) criteria.

Methods A descriptive study was conducted in the Stroke Unity of Hospital Center of Cova da Beira. During 3 months the medical files of all elderly patients (age $\geq 65$ years) admitted with acute cardiovascular disease were reviewed and START criteria applied to the information of medication, at admission and clinic discharge. 